Med Princ Pract 2008;17:171-172

DOI: 10.1159/000112976

\section{Problem-Based Learning: The Right Direction for Medical Teaching?}

\section{P. Ravi Shankar}

Manipal College of Medical Sciences, Pokhara, Nepal

\section{Introduction}

Problem-based learning (PBL) is grounded in the belief that learning is most effective when students are actively involved and learn in the context in which knowledge is to be used [1]. PBL is now an accepted component of medical school programs in the United States, Canada, the United Kingdom, the Middle East and Asia $[2,3]$. The World Health Organization has recommended $\mathrm{PBL}$ of pharmacotherapy as a key component for promoting the more rational use of medicines [4].

PBL is gradually becoming more common in Asian medical schools, especially those in Southeast Asia [5] where the culture values loyalty and deference towards the teacher. Asian students have been described as shy, lacking self-esteem and extremely polite [6]. They are reserved in class for fear of being wrong [6]. Medical professionals who have used PBL with Southeast Asian students have reported weak group process and interaction skills among students.

\section{Experience of the Manipal College of Medical Sciences}

The Manipal College of Medical Sciences (MCOMS), Pokhara, Nepal, admits students from Nepal, India and Sri Lanka for the undergraduate medical (MBBS) course. Students are admitted after 12 years of schooling, which include physics, chemistry and biology in the last 2 years. The 12th standard in South Asia is equivalent to British A levels. Some students also join after completing a degree (3 years of study after the 12th standard). Pharmacology is taught during the first 4 semesters of the MBBS course in an integrated organ-based system with the other basic science subjects (anatomy, physiology, biochemistry, pathology, microbiology and community medicine) [6]. There are regular hospital visits. The clinical subjects are usually taught from the 5th semester.

The Department of Pharmacology conducts problem-stimulated learning (PSL) sessions [7] and has been using this learning modality since the middle of 2001. The clinical Departments of Medicine, Surgery, Obstetrics and Gynecology and Pediatrics have been using PBL since the beginning of 2002. The Departments of Pathology and Radiology have not yet adopted PBL, and it is not a common learning methodology in anatomy, physiology, microbiology and community medicine. PBL sessions do not cut across subjects. The groups are multinational and of both sexes. The facilitators try to smoothen out the group dynamics in case of problems but do not usually provide answers to questions. The students solve the problem in approximately an hour and then present their solutions. During the presentation, the student presenters occupy center stage and the facilitators sit in a corner. The topic then is opened for discussion to the house. After the presentation, the facilitators sum up the discussion and may focus on points which did not emerge or were not emphasized during the presentation and subsequent discussion.

The Department of Pharmacology uses a mixture of didactic lectures and PBL/PSL sessions. The theoretical bases of topics are covered during the didactic lectures and students solve problems in pharmacology and therapeutics during the PBL/PSL (practical) sessions (lasting $2.5 \mathrm{~h}$ ). A class of 37 or 38 students is divided into five groups of 7 or 8 each. Three faculty members/postgraduate students act as facilitators who divide their time among the different groups.

Solving clinical problems, selecting a personal or P-drug for a disease condition, verifying the suitability of the selected P-drug for a particular patient and writing a prescription, analyzing drug advertisements and promotional material and communicating drug and non-drug information to simulated patients are typical exercises carried out during the PBL/PSL sessions.

\section{Evaluation of Our Experiences}

MCOMS is using a modification of PBL which may be more practicable in resource-limited settings. Our overall experiences with the PBL/PSL and the role of facilitators have been positive. Initially it was difficult for facilitators to relinquish the traditional authority associated with a teacher. Resisting the urge to provide answers and directing the students towards solving the problems on their own was sometimes difficult. Not all students participated fully in the group deliberations and activities. Facilitators tried to let the group solve this problem on their own. Sometimes indirect pressure was used to induce participation. Many students eventually did participate, but some proved to be recalcitrant. Formative assessment during the sessions has recently been introduced. Student participation in the group activities, group leadership skills and communication abilities have been assessed.

The large batch size (37 or 38 students) has sometimes created disciplinary problems. With a fellow student on stage and the facilitators sitting in a corner, certain students have tried to take advantage of the situation. Also, students are so used to the concept of a teacher that they constantly turn towards the facilitators even though they sit in a corner.

While the sessions should be continued, modifications could be considered. A greater part of the student learning could be ac-

\section{KARGER}

Fax +4161306 1234

E-Mail karger@karger.ch

www.karger.com
C 2008 S. Karger AG, Basel

1011-7571/08/0172-0171\$24.50/0

Accessible online at:

www.karger.com/mpp 
complished through problem-solving sessions. In subjects that are not using PBL, problem-solving exercises should be introduced. An integrated learning of subjects using clinical problems should be given serious consideration.

Despite all the problems noted, students enjoyed the PBL/PSL sessions. The Department of Pharmacology and other departments at MCOMS were successful in using PBL as a method of student learning.

\section{References}

1 Kwan CY: What is problem-based learning $(\mathrm{PBL})$ ? It is magic, myth and mindset. CDTL Brief 2000;3:1-2.

2 Jonas HS, Etzel SI, Barzansky B: Educational programs in US medical schools. JAMA 1991;266:913-920.

3 Bligh J: Problem-based, small group learning. BMJ 1995;311:342-343.
4 World Health Organization: Promoting Rational Use of Medicines: Core Components. WHO Policy Perspectives on Medicines. Geneva, World Health Organization, 2002.

5 Amin Z, Eng KH, Gwee M, Rhoon KD, Hoon TC: Medical education in Southeast Asia: emerging issues, challenges and opportunities. Med Educ 2005;39:829-832.

6 Eng KH: Can Asians do PBL? CDTL Brief 2000;3:3-4.

7 Shankar PR, Dubey AK, Mishra P, Upadhyay D, Subish P, Deshpande VY: Student feedback on problem-stimulated learning in pharmacology: a questionnaire-based study. Pharm Educ 2004;4:51-56.

\section{Dr. P. Ravi Shankar}

Manipal College of Medical Sciences PO Box 155, Deep Heights, Pokhara (Nepal)

Tel. +977 61440600 , Fax +977 61440260

E-Mail ravi.dr.shankar@gmail.com

\section{Announcement}

13th Health Sciences Center Poster Conference 2008

Faculty of Medicine, Kuwait University, Kuwait, April 22-24, 2008

\section{Call for Abstracts}

Sponsor: Faculty of Medicine, Kuwait University, Kuwait

Venue: Health Sciences Center, Kuwait University, Kuwait

Deadline for submission of abstracts: January 31, 2008

Abstracts must be submitted online: www.hsc.edu.kw/poster2008 or by E-Mail: poster2008@hsc.edu.kw

Keynote speaker: Prof. Abdallah S. Daar, McLaughlin Rotman Centre for Global Health, University of Toronto, Ontario, Canada

Title: Ethical Issues in Medical Practice

Deadline for registration: Onsite

\section{Poster Awards}

A chance to win:

- Dr. Nael Al-Naqeeb Award (for undergraduate students)

- Graduate Award (Basic Sciences)

- Graduate Award (Residents)

- Basic Sciences Award

- Clinical Sciences Award

For further information, contact:

Teena Sadan, Conference Secretary: Tel. +965 498 6418, E-Mail: teena@hsc.edu.kw 